\title{
Outcome of Pregnancy in Women with Mitral Stenosis
}

\author{
NARGIS AKHTER ${ }^{1}$, FAZLUR RAHMAN ${ }^{2}$, MOHAMMAD SALMAN ${ }^{3}$, KHAIRUL ANAM $^{2}$, \\ PERVIN AKTHER, S HAMSUN NAHER ${ }^{1}$, NILUFAR FATAMA ${ }^{2}$, ZAHIDUL HASAN $^{4}$, \\ MA RASHID ${ }^{5}$, MFARUQ ${ }^{6}$, SAJAL KRISHNABANERJEE ${ }^{2}$, KANIZ FATEMA ${ }^{1}$ \\ ${ }^{1}$ Department of Gynae and Obstetrics, Bangabandhu Sheikh Mujib Medical University, Dhaka, ${ }^{2}$ Department of Cardiology, \\ Bangabandhu Sheikh Mujib Medical University, Dhaka, ${ }^{3}$ Department of Cardiology, Anwer Khan Modern Medical College, \\ Dhanmondi, Dhaka, ${ }^{4}$ Department of Medicine, Sir Salimullah Medical College \& Mitford Hospital , Dhaka, ${ }^{5}$ Department of Anatomy, \\ Bangladesh Medical College, Dhanmondi, Dhaka, ${ }^{6}$ Department of Cardiology, National Institute of Cardiovascular Disease, Dhaka. \\ Address for correspondence: Dr. Nargis Akhter, Assistant Professor, Department of Gynae and Obstetrics, Bangabandhu Sheikh \\ Mujib Medical University, Shahbag, Dhaka.E-mail: frahman.card@yahoo.com
}

\begin{abstract}
The aim of this study was to evaluate the maternal and fetal outcome of pregnancy in mitral stenosis. This prospective study was carried out over period of 4 years (2005-2009) involving 50 pregnant patients with mitral stenosis. 30 (60\%) had single valve involvement and mitral stenosis was the most predominant lesion (60\%). 7 patients (14\%) had undergone interventional and surgical correction prior to the onset of pregnancy. 12 (24\%) patients presented at NYHA class III-IV. Women with MS had 10\% pulmonary edema. 8(16\%) developed different types arrhythmia. There was one (1.67\%) meternal death has been reported in this series. The incidence of preterm birth and small for gestational age newborn was $12 \%$ and $14 \%$ respectively. Pregnancy in women with valvular heart diseases associated with remarkable unfavourable effect on maternal and fetal outcome which are related to severity of disease.
\end{abstract}

Keywords: Mitral stenosis; Pregnancy.

\section{Introduction}

Heart disease complicates approximately $1 \%$ of all pregnancy. ${ }^{1}$ Valvular heart disease (VHD) in young women is most commonly due to rheumatic heart disease (RHD).Congenital abnormalities, previous infective endocarditis (IE), may increase the maternal and fetal risks associated with pregnancy. The likelihood of an adverse outcome is related to the type and severity of maternal valvular heart disease and the resulting abnormalities of functional capacity, left ventricular function, and pulmonary pressure. ${ }^{2}$ Mitral stenosis (MS) is the most common rheumatic lesion of heart and also poorly detected condition in our country.

Though the prevalence of pregnancy complicated by RHD has decreased in developed countries, yet RHD is still responsible for the majority of the cause of heart disease in pregnancy in developing countries like Bangladesh. Pregnancy and the peripartum period imposes substantial load on the heart and circulatory system. In women with heart disease changes can lead to rapid clinical deterioration. ${ }^{3}$ The majority of women with cardiac disease can tolerate pregnancy successfully. However in some of the patients with pregnancy cause cardiac therapeutic problems which may threat maternal and fetal well being and survival. ${ }^{4}$ Mitral valve stenosis due to rheumatic fever is the most common form of organic heart disease encountered during pregnancy, and continues to cause maternal and fetal mortality. ${ }^{5,6}$ The present study, therefore, designed to evaluate the effect of MS on maternal and fetal outcome in a group of patients.

\section{Materials and Methods}

This prospective observational study was carried out in three cardiac centres in Dhaka city, Bangladesh, between January 2006 to December 2009.

A total of 50 pregnant women with mitral stenosis (MS) were included in the study. Exclutions included 1) incomplete records, 2) prosthetic heart valve and therapeutic abortion for non-cardiac reasons. Majority of patients were supervised in the cardio obstetric clinic of the respective cardiac centre under joint supervision of an obstetrician and cardiologist. A questionnaire was prepared to collect data of the index population. For each studied patients age, obstetrical and medical history of prenatal care and year of pregnancy were recorded.

Maternal outcome (deterioration of NYHA class, maternal morbidity and mortality, valve thrombosis need for interventional or surgical intervention in pregnancy) and fetal outcome (birth weight, prematurely, congenital malformation) were documented separately.

The data was analyzed and calculated to evaluate maternal as well as fetal outcome. And the results were expressed in the form of table and graph. All values were presented as mean $\pm \mathrm{SD}$. 


\section{Results}

The mean age of the study population was $26 \pm 4.5$ and most of them were in the age group of 16-30 years (TableI). Table 1 also revealed other demographic information and baseline characteristics of the studied cases. 38 (76\%) were in the NYHA functional class I-II and 12 (24\%) were in the class III-IV.

\section{Table-I}

Depicts the baseline characteristics of the study population $(n=50)$

\begin{tabular}{lcc}
\hline Parameters & $\begin{array}{c}\text { Total } \\
\text { number }\end{array}$ & $\begin{array}{c}\text { Percentage } \\
(\%)\end{array}$ \\
\hline Maternal Age (year) & $26 \pm 4.5$ & - \\
$16-30$ & 42 & 84 \\
$>30$ & 8 & 24
\end{tabular}

Parity status

1

2

$\geq 3$

Gravity

Primi Gravidas

Multi Gravidas

Prenetal Care

First trimester

Second trimester

Third trimester

Medical History

Diabetics

32

10

6

2

Pregnancy induced hypertension

Chronic hypertension (PH)

Dyslipidaemia

Coronary heart disease

NYHA functional class

\begin{tabular}{lll} 
Class I-II & 38 & 76 \\
Class III-IV & 12 & 24 \\
\hline
\end{tabular}

30 (60\%) patients had single mitral valve involvement. Surgical or interventional correction of the underlying lesion prior to pregnancy was done in $7(14 \%)$ patients of which 6 (12\%) had mitral valvotomy and 1 (2\%) had valve replacement (Table-II).

Maternal complications included anaemia in 4 (8\%) and gestational diabetes in 2 (4\%) patients. Cardiac complications were observed and there were pulmonery edema in 5 (10\%); atrial fibrillation in $4(8 \%)$, thromboembolism in 2(4\%) and infective endocarditis in 1(2\%) woman. There was 1 (2\%) maternal death (table-III).

Table-II

Showing disease patterns of the study population $(n=50)$

\begin{tabular}{lcc}
\hline Parameters & $\begin{array}{c}\text { Total } \\
\text { number }\end{array}$ & $\begin{array}{c}\text { Percentage } \\
\text { (\%) }\end{array}$ \\
\hline Type of valvular lesions : & 30 & 60 \\
Mitral stenosis (MS) & 9 & 18 \\
Mitral stenosis + regurgitation (MSR) & 2 & 4 \\
Mitral stenosis + Aortic stenosis & 4 & 8 \\
Mitral stenosis + Aortic regurgitation & 4 & 6 \\
Mitral stenosis + Aortic regurgitation+ & 3 & \\
tricuspid regurgitation & & 4 \\
Mitral stenosis + tricuspid stenosis & 2 & \\
(TS) + tricuspid regurgitation (TR) & & \\
No. of valve involvement : & & 60 \\
Single valve involvement & 30 & 40 \\
Multiple valve involvement & 20 & \\
Interventional /Surgical correction prior to pregnancy : \\
(a) Mitral valvotomy & & \\
(i) Closed mitral valvotomy & 2 & 4 \\
(ii) Balloon mitral valvotomy & 4 & \\
\hline
\end{tabular}

Table-III

Demonstrate Complications in Pregnancy $(n=50)$

\begin{tabular}{lcc}
\hline Parameters & $\begin{array}{c}\text { Total } \\
\text { number }\end{array}$ & $\begin{array}{c}\text { Percentage } \\
\text { (\%) }\end{array}$ \\
\hline Non cardiac: & & \\
Anaemia & 4 & 8 \\
Placenta previa & 2 & 4 \\
Placental abruption & 1 & 1 \\
Gestational diabetic & 2 & 4 \\
Postpartum hemorrhage & 1 & 2 \\
Cardiac: & & \\
Pulmonary edema & 5 & 10 \\
Arrhythmias & & \\
(i) Atrial fibrillation (AF) & 4 & 8 \\
(ii) Supraventricular tachycardia(SVT) & 2 & 4 \\
(iii) Venticular ectopics (VE) & 1 & 2 \\
(iv) Ventriculer tachycardia (VT) & 1 & 2 \\
Thromboembolism & 2 & 4 \\
Infective endocarditis (IE) & 1 & 2 \\
Maternal death & 1 & 2 \\
\hline
\end{tabular}


Overall, the mean gestational age at delivery was $32 \pm 4.20$ weeks and was significantly lower in patients with NYHA class III \& IV. Labor was induced in 4(8\%) women for obstetrical indications : poor biophysical profile; pregnancy beyond 40 weeks, premature rupture of membrane, intrauterine growth retardations and pregnancy induced hypertension. Majority (90.18\%) of the patients had vaginal delivary and birth weight was $6 \pm 7 \mathrm{~kg}$. Incidence of preterm small for gestational age and still birth was $6(12 \%) \%$; $7(74 \%) \%$ and $1(2 \%)$ respectively (Table-IV).

Table-IV

Revealed delivery characteristics and perinatal outcomes $(n=50)$

\begin{tabular}{lcc}
\hline Parameters & $\begin{array}{c}\text { Total } \\
\text { number }\end{array}$ & $\begin{array}{c}\text { Percentage } \\
\text { (\%) }\end{array}$ \\
\hline (i) Gestational age (week) & $32 \pm 4.20$ & - \\
(ii) Labor & 46 & 92 \\
a) spontoneous & 4 & 8 \\
b) induced & & \\
(iii) Mode of delivery : & 44 & 88 \\
a) viginal delivery & 6 & 12 \\
b) Cesarean section & & \\
(iv) Fetal outcome : & $6 \pm 7$ & - \\
a) Birth weight (kg) & 6 & 12 \\
b) preterm & 7 & 14 \\
c) small for gestational age & 1 & 2 \\
d) Still birth & & \\
\hline
\end{tabular}

\section{Discussion}

Heart disease remains the third most common nonobstetric cause of maternal death following hypertension and pulmonary embolism. ${ }^{5}$ The commonest cardiac lesion is rheumatic origin followed by the congenital one. ${ }^{6}$ The results of our study demonstrate a significant impact of MS on both maternal and fetal outcomes.

Maternal outcome : Women with MS had a high rate of clinical deterioration and a marked increase in morbid events during pregnancy, including $\mathrm{CHF}$, arrhythmias and need to either initiate or increase cardiovascular drug therapy or to hospitalize patients during pregnancy. The haemodynamic change that occur during pregnancy have a profound effect on the patient with cardiac disease. ${ }^{7-11,12}$ Haemodynamic changes increases cardiac work. Combined effect of haemodynamic changes and heart may exceed the limited functional capacity of heart. ${ }^{7,11}$ When this happen, sudden death or more commonly congestive heart failure (CHF) will occur. As a result of the deleterious effects of pregnancy on cardiac disease maternal mortality may be high as $10 \%$ for all cardiac problem. $7,9,10,13,14,15$

There are several periods during pregnancy when the danger of cardiac detoriation is specially high. The first is between 12 and 32 weeks of gestation. The most critical period is between 28 and 32 weeks. About 50\% patients develop heart failure in antepartum period. 7,8,9,10,11,6,7,8,14,16 The second dangerous period is during labor and delivery. The large and increase in blood volume is more then many cardiac patients can tolerate and CHF occur infrequently. Particularly predispose CHF. ${ }^{7-12,14,15,17,18}$ Final dangerous time for the pregnant patients with MS is 4 to 5 day after delivery. CHF after develops at this period.

Fetal outcome : In addition to the effect on maternal morbidity, the present study also demonstrated an effect of MS on fetal outcome. Pregnancy in our patients was associated with an increased incidence of IUGR, preterm deliveries, and lower birth weight, especially in case with moderate and severe stenosis of the mitral valve. Hemodynamic compromise secondary to valvular stenosis and the resulting decrease in uterine blood flow are probable explanations for the high incidence of impaired intrauterine fetal growth seen in this study.

Valvular repair during pregnancy: Valvular repair, either surgically or by percutaneous balloon valvuloplasty, is the procedure of choice in symptomatic, nonpregnant patients with MS. Successful cardiovascular surgery has been reported during pregnancy. ${ }^{20,21}$ In our study 2(4\%) patients had closed mitral valvotomy and 4(8\%) patients had balloon mitral valvuloplasty.

\section{Conclusion}

Valvular heart disease (VHD) may have a significant impact on the course and outcome of pregnancy with implication for fetal as well as maternal health. Optimally serious symptomatic VHD should be detected and treated before pregnancy because of its deleterious impact on maternal and fetal outcome of pregnancy. The result of the present study demonstrate an important effect of MS on both metarnal and fetal outcome of pregnancy. The results of the study indicate that whether a pregnant women is known to have MS or is diagnosed during pregnancy, however, it is imperative that she is managed by an experienced multidisciplinary team including an obstetrician/ perinatologist, cardiologist and obstetric 
anesthesiologist. Although medical therapy may alleviate symptoms of heart failure in some patients, definitive intervention either with percutaneous balloon valvuloplasty or with surgical valve replacement may be necessary. The possible benefit of the procedures, however, should be carefully weighed against its maternal risks during pregnancy.

\section{Acknowledgement}

As author's we are grateful to Kasfiqur Rahman, Farzia Hasan Mumu, Sharmin Hasan Monti for their utmost help in the preparation of this manuscript.

\section{References}

1. Thilen U, Olsson SB. Pregnancy and heart disease: a review. Eur obset Gynaecol Reprod Biol 1997; 75: 43-50

2. Sharon C, Reimold and John D. Rutherford. Valvular Heart disease in Pregnancy. N Engl J Med 2003; 349: 52-58.

3. Uri Elkayam, Braunwald Heart Disease. $5^{\text {th }}$ ed. philadelphia; WB Saunders Company :1997.P 1843-57

4. H. Sanhney, N Aggarwal, V. Suri, K. Vasihta, Y. Sharma, A. Groven. Maternal and perinatal outcome in rheumatic heart disease. International Journal of Gynecology and Obstetrics 2003; 80: 9-14.

5. De Dutta. Text book of obstetrics $4^{\text {th }}$ ed. India: New Central Book Agency (P) Ltd, 1998. P 295-300.

6. Gleichen M, Midwall J, Hoch beryer D. Eisenmenger syndromes and pregnancy. Obs Gyneecol suru 1997; 34: 721.

7. Szekely P, Snaith L.Metanal mortality in rheumatic heart disease.In: Szekely P, Snaith L ed. Heart disease and pregnancy. Edinburgh and London. Churchill Livingston, 1971; 129-33.

8. Kahler RL. Cardiac Disease.In: Burrow GN, Ferris TF, eds. Medical complication during pregnancy. Philadelphia, London, Torento: WB Saunders, 1975; 105-45.

9. Ternando Arias; Cardiac Disease and pregnancy; Practical Guide to High risk pregnancy and delivery: Second edition; 200; 213-29.
10. Szekely P, Snaith L. Heart Diease and Pregnancy. Edinburgh, Churchill; Livingstone, 1974-21-79.

11. Mefanl PB, Dorann TC, Lamki H et al. Pregnancy complicated by maternal heart disease, Br.J Obstet Gynacol;1995; 861-67.

12. Ueland K. Cardiovascular diseases Complicating Pregnancies. Clin Obstet Gynacol; 21-49.

13. D.C.Dutta; Heart Disease in Pregnancy, Tex Book of Obstetrics; Fifth edition 2000; 293-98.

14. DG Julian, JC Cowan JM. Meleanchan ; Pregnancy and the heart, Cardiology seventh edition 372-75.

15. MC Anulty JH, Metealfe J, Ueland K The heart and certain physiological condition. in Schlant RC, Alexander RW, Rourke RA, et.al(eds) The Heart, $8^{\text {th }}$ New York, Mecgraw Hill, 1994:chap 13 PP 2011-46.

16. Porenta G., Lang I, Christ G, Schemper M. Predictors of outcome on mitral stenosis. N Engl J Med 2000; 343: 61117 .

17. Julian DG, Camm AJ, Fox KM, Hall RJAC, Poole-Wilson PA ed. Disease of the heart. $2^{\text {nd }}$ ed.

18. Sullivan JM, Raman m than KB. Management of Medical Problem in Pregnancy-Severe Cardiac Disease. N Engl J Med 1985; 131: 304-09.

19. Reimold S.C., Rutherford J.D. Valvular heart disease in pregnancy, N Engl J Med.2003; 76: 202-12.

20. Bernard lungi Mitral Valve Disease; Medicine International, 2002: 84-87.

21. Hameed A, Karaalp IS, Tummale PP et al. The effect of Valvular Heart Disease on Metarnal and Fetal Outcome of Pregnancy. J Am Coll Cardiol. 2001; 37: 893-9.

22. Whittemere R, Hobbins JC, Engle MA. Pregnancy and its outcome in with and without surgical treatment of congenital heart disease. Am J Cardiol. 1982; 50: 641-51.

23. Vaska PL. Cardiac surgery in special population. Part 2: Women; Pregnant patient and Jehvah's Witnss. AACN Clinical Issues 1997; 8: 59-66. 